\title{
Autism in Down's syndrome: presentation and diagnosis
}

\author{
M. GHAZIUDDIN, L. Y. TSAI \& N. GHAZIUDDIN \\ Division of Child and Adolescent Psychiatry, University of Michigan, Ann Arbor, \\ Michigan, USA
}

\begin{abstract}
Although autism is said to occur rarely with Down's syndrome, it may be more common in those persons with Down's syndrome who also show superimposed behavioural problems. In this brief report, the authors explore this possibility. They describe three patients with Down's syndrome who were referred for behavioural reasons and were found to have coexisting autism. They propose that a systematic study of the association of these two conditions may have implications on research and clinical practice.
\end{abstract}

\section{INTRODUCTION}

Prevalence of behavioural and psychiatric abnormalities in persons with Down's syndrome is well-documented (Lund, 1988). A variety of superimposed psychiatric disorders have been described in this population. These include: schizophrenia (Eaton \& Menolascino, 1982); depression (Warren et al., 1989); bipolar disorder (Sovner, 1991); conduct disorder (Gath \& Gumley, 1986); and dementia (Wisniewski et al., 1985). While the prevalence of certain disorders, such as dementia, is raised in Down's syndrome, it has been claimed that the association of autism and Down's syndrome is uncommon (Rutter \& Schopler, 1988). In their epidemiological survey of social impairments in 35000 children under the age of 15 years, Wing \& Gould (1979) found that, out of a total of 30 children with Down's syndrome, 27 were classified as sociable severely retarded; one as aloof; one as passive and odd; and only one as autistic (italics added). Although several case reports have documented the occurrence of autism in various medical disorders, few have described its association with Down's syndrome. Wakabayashi (1979) reported a 7 year-old boy with Down's syndrome who also met the criteria for autism. More recently, Bregman \& Volkmar (1988) described a 12-year-old girl who appeared to suffer from both these disorders. In this report, the authors present three more cases of autism and Down's syndrome, and propose that the association is perhaps more common than generally believed.

Correspondence: $\operatorname{Dr} M$. Ghaziuddin, Child and Adolescent Psychiatry-Taubman Center Box 0390, University of Michigan Medical Center, 1500 E Medical Center, Ann Arbor, MI 48109-0390, USA. 


\section{CASE REPORTS}

\section{Patient 1}

M. is a 17-year-old youngster with Down's syndrome. He lives with his parents and attends an educational programme for trainable (moderately) mentally retarded children. He is classified as moderately mentally retarded; on the revised Wechsler Adult Intelligence Scale (Wechsler, 1981), his Verbal IQ is 52, Performance IQ is 49 and Full Scale IQ is 48.

The presenting symptoms were frequent crying spells, irritability, increasing social withdrawal and sleep disturbance, all of about 8-12 months' duration. There was no family or past history of a major psychiatric disorder or mental retardation.

Developmental history revealed that he was born after a normal pregnancy and delivery. He was diagnosed as suffering from Down's syndrome at about 9 months of age by a chromosomal analysis. He was described as a 'good baby' who sat at 5 months and started walking at 11 months of age. However, his speech was delayed. He spoke his first words at about 3 years of age. He seldom used pronouns, and at the time of referral, his speech and language assessment showed that he functioned at about the 4 year level in his receptive language ability. He could initiate two to three phrases, but had difficulty with longer units. He spoke in a nasal tone and also had the habit of making irrelevant remarks and repeating the other person's phrases. His play was dull and repetitive, such as rolling a toy over and over again. He had difficulty in interacting with children of his age and preferred to be alone. He showed an undue attachment to certain objects, such as toy trucks. He enjoyed listening to music but insisted on playing the same records.

When interviewed, he seemed to take little notice of the examiners. He repeated the examiners' questions and sat rocking continuously. He looked sad and unhappy. A provisional diagnosis of depressive illness was made. In addition, the present authors felt that he also met the criteria for autistic disorder as defined by the DSMIII-R (APA, 1987). These criteria were: gross impairment in the ability to make peer relationships; marked impairment of reciprocal social interaction; inability to start and maintain conversation; lack of social play; marked abnormalities in the form and content of speech such as echolalia; undue attachment to objects; marked distress over changes in environment; insistence on following the same routines; restricted range of interests etc. In order to supplement the clinical impression, he was also rated on the modified Autism Behavior Checklist (Krug et al., 1980). Based on information obtained independently from both the parents, he scored 69 and 66 on the checklist as shown in Table 1 . His depression was treated with fluoxetine hydrochloride, details of which are described elsewhere (Ghaziuddin \& Tsai, 1991). After a month, his mood began improving. He stopped crying and also started eating his meals with his family. His sleep also improved. However, he continued to show autistic features such as aloofness; impairment of reciprocal social interaction, abnormalities of speech such as echolalia; undue attachment to objects; and insistence on following routines. 
Table 1. Scores on the ABC checklist (Krug et al., 1980) in each symptom area of the three patients

\begin{tabular}{|c|c|c|c|c|c|c|c|}
\hline \multirow[b]{2}{*}{ Symptom area } & \multirow{2}{*}{$\begin{array}{l}\text { Mean } \\
\text { scores } \\
\text { Krug } \\
\text { et al.'s } \\
\text { autistic } \\
\text { sample }\end{array}$} & \multicolumn{2}{|c|}{ Patient 1} & \multicolumn{2}{|c|}{ Patient 2} & \multicolumn{2}{|c|}{ Patient 3} \\
\hline & & $\begin{array}{l}\text { Rated } \\
\text { by } \\
\text { mother }\end{array}$ & $\begin{array}{l}\text { Rated } \\
\text { by } \\
\text { father }\end{array}$ & $\begin{array}{l}\text { Rated } \\
\text { by } \\
\text { mother }\end{array}$ & $\begin{array}{l}\text { Rated } \\
\text { by } \\
\text { father }\end{array}$ & $\begin{array}{l}\text { Rated } \\
\text { by } \\
\text { mother }\end{array}$ & $\begin{array}{l}\text { Ratec } \\
\text { by } \\
\text { father }\end{array}$ \\
\hline Sensory & $12 \cdot 67$ & 9 & 9 & 10 & 6 & 26 & 12 \\
\hline Relating & 23.99 & 8 & 8 & 26 & 26 & 35 & 23 \\
\hline Body/object use & $15 \cdot 79$ & 9 & 9 & 20 & 17 & 33 & 28 \\
\hline Language & $12 \cdot 20$ & 26 & 25 & 19 & 12 & 23 & 15 \\
\hline Social & $12 \cdot 80$ & 17 & 17 & 13 & 13 & 25 & 17 \\
\hline Total & $77 \cdot 49$ & 69 & 66 & 88 & 74 & 142 & 95 \\
\hline
\end{tabular}

\section{Patient 2}

K., a 21-year-old white male, was diagnosed with Down's syndrome at birth. He had been suspected of showing autistic traits by the school personnel but a diagnosis of autism had never been made. Parents referred him to rule out this disorder so that access to an appropriate vocational training programme could be arranged.

K. was born after an unplanned but normal pregnancy. Down's syndrome was diagnosed immediately after birth because of facial appearance and was later confirmed by a chromosomal analysis. All his milestones were delayed. For example, he started walking when he was 2 years old. His mother reported that she could not recall if $\mathrm{K}$. ever wanted to be held or cuddled. He was always content to be left alone and never played with other children of his age. His play was generally rigid and mechanical, such as the lining up of objects and dusting them. Because of his withdrawn behaviour, hearing impairment was suspected but no abnormality was found. Other behaviours reported were repetitive movements, such as frequent tapping of feet, flapping of arms, constant rocking of the body, compulsive touching of people, and an indiscriminate habit of feeling the texture of objects. He was placed in a programme for moderately mentally retarded children, and according to school reports, he stood out among others by his reluctance to join in any group activity. He seldom used spontaneous speech although he would respond with one or two words to questions from his teacher. On the Leiter International Performance Scale, he scored 40, which placed him in the moderately retarded range.

$\mathrm{K}$. lived with his biological parents, both of whom were in good mental and physical health. He had three older brothers, one of whom also had Down's syndrome but did not have the problems of social impairment which $\mathrm{K}$ had.

On mental status examination, details about his behaviour as given in the history were confirmed. He showed repetitive movements and appeared totally indifferent to the interview. He made no eye contact with the examiners, but rushed out to touch them. He did not make any attempt to initiate conversation and when forced to do so, responded by monosyllables. 
Based on the history and the examination, $\mathrm{K}$. was given a diagnosis of autistic disorder (DSM-III-R, APA, 1987), as indicated, among other features, by his markedly abnormal social play; gross impairment in the ability to make peer friendships; marked impairment of communicative gesture, mime and facial expression; marked impairment in the form and content of speech; impairment in the ability to initiate or sustain conversation; persistent preoccupation with parts of objects including their texture; and insistence on following routines (e.g. dusting). On the modified Autism Behavior Checklist, scores given by his parents were 88 (mother) and 74 (father), which further supported the diagnosis of autism (Table 1).

\section{Patient 3}

D. is a 14-year-old, Caucasian youngster with Down's syndrome and severe mental retardation with a full scale IQ of 23 on the Stanford-Binet test (Thorndike et al., 1986). He lives at a centre for mentally retarded children and visits his home every weekend.

He was referred by his parents for increasing behavioural problems, which typically consisted of unpredictable aggressive outbursts, hyperactivity, head-banging and other self-injurious behaviours. These symptoms, though of a long standing nature, apparently deteriorated a few months prior to the referral possibly coinciding with staff changes at school.

It was reported that D. had a great difficulty in accepting changes in routine. In addition, he rarely participated freely in leisure time activities. He did not like interacting with other residents at the centre and had to be physically prompted to do so. He liked to sit by himself and feel the texture of books. He was extremely upset by small changes in the environment. $\mathrm{He}$ insisted on watching the same television programme (Sesame Street) and on listening to the same piece of music whenever possible. He could follow simple directions with adequate time to process, but could not imitate gestures. He used a vocabulary of two to five words; these were often used in a repetitive manner with little regard to the social context. His nonverbal communication was also impaired. His eye contact was minimal. Occasionally, he made grunting noises, and showed abnormal movements such as body-rocking. $\mathrm{He}$ had a habit of sniffing things such as furniture and also showed an undue attachment to certain objects such as his record player. Apart from his myopia, he had no significant medical or surgical history.

There was a history of mental illness in the family. His father, aged 43 years, a professor of physics, had been treated for depression. He reported that, in his younger years, he was very much like his son so far as social interaction was concerned. He had no friends and preferred the company of his computer. The patient's mother, aged 50 years, had also been treated for clinical depression. There was no history of any developmental disorders or mental retardation in the family.

D. was the product of a full-term normal delivery. On the basis of his facial appearance, he was diagnosed as suffering from Down's syndrome; this was later confirmed by means of a chromosomal analysis which found trisomy 21 . His motor milestones, such as sitting and walking without support, were within normal limits. 
However, his speech was substantially delayed. After being classified as severely mentally retarded, he was placed in a programme for mentally retarded children. However, his education was marred by frequent changes as a result of his father's employment. $\mathrm{He}$ attended a special school for about 2 years in his native Brazil, before the family moved to England. While in England, he went to two different schools, for a total period of 2 years and then returned to Brazil. Finally, when he was 8 years old, his family came to the US. Parents reported that his behavioural problems progressively deteriorated as he reached adolescence and as he moved from one country to another.

During interview, he had the appearance of a youngster with Down's syndrome. $\mathrm{He}$ showed frequent rocking movements and totally ignored the examiners. His eye contact was minimal. Halfway through the interview, he started making grunting noises and wringing his hands. He would occasionally smell his fingers and repeat words such as "Yeah! Yeah!" over and over.

In addition to Down's syndrome, it was felt that D. also met the DSM-III-R criteria for autistic disorder. These, adjusted for his mental age, were as follows: lack of awareness of the existence of others (e.g. treating people as inanimate objects, 'looking through people'); lack of social play; impaired capacity to imitate; impaired nonverbal communication (as shown by his minimal eye contact and gesture); delay and abnormalities in the production and in the form of speech (e.g. making grunting sounds, repeating words in an irrelevant manner); undue attachment to certain objects (e.g. his record player); stereotyped body movements; and marked distress over small changes in the environment. On the modified Autism Behavior Checklist, his total scores given by his mother and father was 142 and 95, respectively, which further supported the diagnosis of autism, as shown in Table 1.

\section{DISCUSSION}

This report describes the presentation and diagnosis of autism in Down's syndrome. In the first two patients, the diagnosis was not difficult, while in the third patient, it was complicated by the presence of severe mental retardation. Over three-quarters of autistic children are mentally retarded, and about half have an IQ below 50. Diagnosis of autism in severe mental retardation is a matter of ongoing debate (Volkmar \& Cohen, 1988). In general, children with global mental retardation show a delay in all areas of development consistent with their mental age; where as those with autism show discrepancies in development of a characteristic kind (Wing, 1979). Although the prevalence of autistic features of social and communication impairment rises with the degree of mental retardation, even some profoundly retarded persons are sociable (Wing, 1981). Both the low-IQ and the high-IQ autistic children show the main features of autism, although those with a lower IQ are more likely to show such deviant social behaviours as touching or smelling people; stereotypies; and self-injury (Bartak \& Rutter, 1976). Thus, it is possible to make a diagnosis of autism in the presence of severe mental retardation, on the basis of the characteristic pattern of social and communication impairment. This is further strengthened by the presence of certain deviant social behaviours such as smelling and touching of objects, and self-injury, as in the patient described above. 
The fact that all the three patients were referred to the same clinic over a 12 -month period, raises the possibility that the association of the two conditions may be more common than generally recognized. It has been estimated that for most Western countries, the prevalence of Down's syndrome is around one per thousand (Kushlick \& Blunden, 1975). In the present authors local school district, out of a total population of 39000 (kindergarten to grade 12), the number of individuals with Down's syndrome is probably about 40 . Out of these, two patients presented to our clinic with a diagnosis of both autism and Down's syndrome, while the third patient, $K$, , belonged to another school district. If this estimate is correct, it suggests that for every 100 persons with Down's syndrome, there may be about four or five with coexisting autism.

The present author's suggestion that $4-5 \%$ of persons with Down's syndrome may meet the criteria for autism is consistent with the findings of Gillberg et al. (1986). In a population-based study in Sweden, they found that one out of $20(5 \%)$ children with Down's syndrome had coexisting autism. A study of adults with Down's syndrome found even higher rates. In a Danish epidemiological study, Lund found that autism constituted the most common additional psychiatric diagnosis, followed by dementia (Lund, 1988). Out of a total of 44 adults with Down's syndrome, five $(10 \%)$ had coexisting autism, four had dementia and two were diagnosed as suffering from 'behaviour disorder'. Although these studies support our view regarding the prevalence of autism in Down's syndrome, research employing large-sized samples is essential to further clarify the issue. It is important that the diagnosis of autism is not missed when it occurs in Down's syndrome. Having access to autistic services and to professionals experienced in the management of autism, may be of benefit to those who suffer from both Down's syndrome and autism. For example, a child with the dual diagnosis of Down's syndrome and autism may be better placed in a programme which incorporates a structured routine taking his or her autistic tendencies into consideration, than in one meant essentially for children with Down's syndrome.

The reason why this combination is probably underdiagnosed stems from the belief in the 'Down's syndrome personality'. Persons with Down's syndrome are said to be affectionate and easy in temperament. However, studies on temperament in Down's syndrome suggest that a subgroup of individuals may show behavioural problems (Gibson, 1978). It is possible that this subgroup may include persons with autism and other behavioural and psychiatric disorders. Although, no causal relationship can be proposed between the two conditions, it is interesting that certain pathophysiologic aberrations are common to both. For example, both autism and Down's syndrome are associated with neuropathological findings such as heteropias or focal abnormal collections of gray matter in cerebellar and cerebral cortices (Piven et al., 1990; Zellweger, 1977). These structural abnormalities, although not specific to either of the disorders, might reflect the altered patterns of functional organization common to both. Also, it is possible that autistic dysfunction in patients with Down's syndrome might be due to the direct or indirect result of trisomy 21 itself, which is often accompanied by various organic deficits (Lund, 1988).

In conclusion, persons with Down's syndrome who present with behavioural problems, may suffer from coexisting autism, which is likely to be missed. Early 
recognition of this association is important, as these persons may benefit from gaining access to the appropriate services. While there is no evidence for a causative link between the two conditions, it is possible that they share certain common features which need to be investigated further.

\section{REFERENCES}

American Psychiatric Association (1987) Diagnostic and Statistical Manual, 3rd ed, revised. APA, Washington, DC.

Bartak L. \& Rutter M. (1976) Differences between mentally retarded and normally intelligent autistic children. Fournal of Childhood Schizophrenia 6, 109-20.

Bregman J.D. \& Volkmar F.R. (1988) Autistic social dysfunction and Down syndrome. Foumal of the American Academy of Child and Adolescent Psychiatry 27, 440-1.

Eaton L.F. \& Menolascino F.J. (1982) Psychiatric disorders in the mentally retarded: types, problems, and challenges. American fournal of Psychiatry 139, 1297-303.

Gath A. \& Gumley D. (1986) Behaviour problems in retarded children with special reference to Down's syndrome. British Fournal of Psychiatry 149, 156-61.

Ghaziuddin M \& Tsai L. (1991) Depression in autistic disorders. British fournal of Psychiatry $159,721-3$.

Gibson D. (1978) Down's Syndrome: The Psychology of Mongolism. Cambridge University Press, Cambridge.

Gillberg C., Persson E., Grufman N. \& Themner U. (1986) Psychiatric disorders in mildly and severely mentally retarded urban children and adolescents: Epidemiological aspects. British Foumal of Psychiatry 149, 68-74.

Krug D.A., Arick J. \& Almond P. (1980) Behavior checklist for identifying severely handicapped individuals with high levels of autistic behavior. Fournal of Child Psychology and Psychiatry 21, 221-9.

Kushlick A. \& Blunden R. (1975) The epidemiology of mental subnormality. In: Mental Deficiency: The Changing Outlook, 3rd edn, A.M. Clarke \& A.D.B. Clarke (eds), pp. 31-81. The Free Press, New York, NY.

Lund J. (1988) Psychiatric aspects of Down's syndrome. Acta Psychiatrica Scandinavica 78, 369-74.

Piven J., Berthier M.L., Starkstein S.E., Nehme E., Pearlson G. \& Folstein S. (1990) Magnetic resonance imaging evidence for a defect of cerebral cortical development in autism. American Foumal of Psychiatry 147, 734-9.

Rutter M. \& Schopler E. (1988) Autism and pervasive developmental disorders. In: Assessment and Diagnosis in Child Psychopathology, M. Rutter, A.H. Tuma \& I.S. Lann (eds), pp. $408+34$. David Fulton Publisher, London.

Sovner R. (1991) Divalproex-responsive rapid cycling bipolar disorder in a patient with Down's syndrome: implications for the Down's syndrome mania hypothesis. fournal of Mental Deficiency Research 35, 171-3.

Thorndike R.L., Hagen E.P. \& Sattler J.M. (1986) Stanford-Binet Intelligence Scale, 3rd ędn. The Riverside Publishing Company, Chicago, IL.

Volkmar F.R. \& Cohen D.J. (1988) Classification and diagnosis of childhood autism. In: Diagnosis and Assessment in Autism, E. Schopler \& G.B. Mesibov (eds), pp. 71-89. Plenum Press, New York, NY.

Wakabayashi S. (1979) A case of infantile autism associated with Down's syndrome. Fournal of Autism and Developmental Disorders 9, 31-6.

Warren A.C., Holroyd S. \& Folstein M.F. (1989) Major depression in Down's syndrome. British Fournal of Psychiatry 155, 202-5.

Wechsler D. (1981) WAIS-R Manual. Psychological Corporation, New York, NY. 


\section{M. Ghaziuddin et al.}

Wing L. (1979) Differentiation of retardation and autism from specific communication disorders. Child: care, health and development 5, 57-68.

Wing L. (1981) Language, social and cognitive impairments in autism and severe mental retardation. Fournal of Autism and Developmental Disorders 11, 31-44.

Wing L. \& Gould J. (1979) Severe impairment of social interaction and associated abnormalities in children: epidemiology and classification. Fournal of Autism and Developmental Disorders 9, 11-29.

Wisniewski K.E., Wisniewski H.M. \& Wen G.Y. (1985) Occurrence of neuropathological changes and dementia of Alzheimer's disease in Down's syndrome. Annals of Neurology 17, 278-82.

Zellweger H. (1977) Down syndrome. In: Handbook of Clinical Neurology,Vol. 31, P.J. Vinken \& G.W. Bruyn (eds), pp. 367-469. North Holland Publishing Company, Amsterdam.

Received 29 May 1991; revised 26 fuly 1991 
This document is a scanned copy of a printed document. No warranty is given about the accuracy of the copy. Users should refer to the original published version of the material. 